\title{
Maternal genitourinary infections and poor nutritional status increase risk of preterm birth in Gasabo District, Rwanda: a prospective, longitudinal, cohort study
}

Etienne Nsereko ${ }^{1 *}$ D, Aline Uwase ${ }^{1}$, Assumpta Mukabutera ${ }^{2}$, Claude Mambo Muvunyi ${ }^{3}$, Stephen Rulisa ${ }^{3}$, David Ntirushwa ${ }^{3}$, Patricia Moreland ${ }^{4}$, Elizabeth J. Corwin ${ }^{5}$, Nicole Santos ${ }^{6}$, Manasse Nzayirambaho ${ }^{2}$ and Janet M. Wojcicki ${ }^{6}$

\begin{abstract}
Background: Preterm birth (PTB) is a leading cause of early childhood mortality and morbidity, including long-term physical and mental impairment. The risk factors for PTB are complex and include maternal nutritional status and infections. This study aimed to identify potentially modifiable risk factors for targeted interventions to reduce the occurrence of PTB in Rwanda.

Methods: We conducted a prospective, longitudinal cohort study of healthy pregnant women aged 18 to 49 years. Women at 9-15 gestational weeks were recruited from 10 health centers in Gasabo District, Kigali Province between September and October 2017. Pregnancy age was estimated using ultrasonography and date of last menstruation. Anthropometric and laboratory measurements were performed using standard procedures for both mothers and newborns. Surveys were administered to assess demographic and health histories. Categorical and continuous variables were depicted as proportions and means, respectively. Variables with $p<0.25$ in bivariate analyses were included in multivariable logistic regression models to determine independent predictors of PTB. The results were reported as odds ratios (ORs) and 95\% confidence intervals (Cl), with statistical significance set at $p<0.05$.

Results: Among 367 participants who delivered at a mean of $38.0 \pm 2.2$ gestational weeks, the overall PTB rate was $10.1 \%$. After adjusting for potential confounders, we identified the following independent risk factors for PTB: anemia (hemoglobin < $11 \mathrm{~g} / \mathrm{dl}$ ) (OR: 4.27; 95\%Cl: 1.85-9.85), urinary tract infection (UTI) (OR:9.82; 95\%Cl: 3.88-24.83), chlamydia infection (OR: 2.79; 95\%Cl: 1.17-6.63), inadequate minimum dietary diversity for women (MDD-W) score (OR:3.94; Cl: 1.57-9.91) and low mid-upper arm circumference (MUAC) <23 cm (OR: 3.12, 95\%Cl; 1.31-7.43). indicators of nutritional inadequacy (low MDD-W and MUAC) predicted risk for low birth weight (LBW) but only UTI was associated with LBW in contrast with PTB.

* Correspondence: etiennen70@gmail.com

'University of Rwanda College of Medicine and Health Sciences School of Health Sciences, P.O. Box: 3538, Kigali, Rwanda

Full list of author information is available at the end of the article

(c) The Author(s). 2020, corrected publication 2022. Open Access This article is licensed under a Creative Commons Attribution 4.0 International License, which permits use, sharing, adaptation, distribution and reproduction in any medium or format, as long as you give appropriate credit to the original author(s) and the source, provide a link to the Creative Commons licence, and indicate if changes were made. The images or other third party material in this article are included in the article's Creative Commons licence, unless indicated otherwise in a credit line to the material. If material is not included in the article's Creative Commons licence and your intended use is not permitted by statutory regulation or exceeds the permitted use, you will need to obtain permission directly from the copyright holder. To view a copy of this licence, visit http://creativecommons.org/ licenses/by/4.0/. The Creative Commons Public Domain Dedication waiver (http://creativecommons.org/publicdomain/zero/1. 0/) applies to the data made available in this article, unless otherwise stated in a credit line to the data. 
(Continued from previous page)

Conclusion: Targeted interventions are needed to improve the nutritional status of pregnant women, such as maternal education on dietary diversity and prevention of anemia pre-pregnancy. Additionally, prevention and treatment of maternal infections, especially sexually transmitted infections and UTIs should be reinforced during standard antenatal care screening which currently only includes HIV and syphilis testing.

Keywords: Infection, Nutrition, Risk factors preterm birth

\section{Background}

Preterm birth (PTB), defined as birth before a gestational age of 37 weeks, is the most frequent cause of neonatal deaths and the leading cause of under-five mortality [1]. PTB is categorized into four categories: late preterm (34-36 weeks), moderate preterm (32-33 weeks), very preterm (28-31 weeks), and extremely preterm $(<28$ weeks) $[1,2]$. PTB-related survival is a function of many factors but is negatively impacted by earlier gestational age [3]. Regardless of the cause, PTB can be spontaneous, medically indicated, or due to premature rupture of the membranes [4]. PTB rates are increasing globally and about 15 million PTBs documented annually, with low and middle-income countries in sub-Saharan Africa contributing $60 \%$ of the global figure $[1,5]$. Prematurity impacts short-term survival by increasing mortality due to complications [6]. Even beyond the neonatal period, survivors can face life-long consequences such as impaired neurodevelopment leading to a risk of cerebral palsy, learning impairment, and visual disorders [7].

Numerous risk factors have been associated with PTB, including advanced and younger maternal age [8], short interval between births [9], maternal underweight and poor nutrition [10], maternal non-communicable and infectious diseases, and cervical incompetence [11]. Psychological and behavioral risk factors for PTB include substance abuse and cigarette smoking $[12,13]$. Bacterial vaginosis, a lower genital tract infection characterized by a change in the normal vaginal flora [14], urinary tract infections (UTIs) $[15,16]$, and sexually transmitted infections (STIs) [17, 18] have all been associated with higher risk of PTB. Several other subclinical infections (both systemic and vaginal) has been associated with a higher risk for PTB, suggesting that inflammation is a shared pathway to PTB $[19,20]$.

In addition to infection, malnutrition increases the risk of PTB [21]. Anemia and malnutrition increase the risk of PTB [22] by dulling the immune response and increasing susceptibility to infection [19].

With an estimated PTB rate of 10\% [23], prematurity is the primary risk factor for neonatal mortality in Rwanda. Anemia in pregnancy is common in Rwandan women as are micronutrient deficiencies and maternal infection [24, 25]. To our knowledge, no study has been conducted to identify the infection and nutrition-related risk factors associated with PTB in Rwanda.

The primary aim of this study was to identify potentially modifiable risk factors for PTB so as to subsequently facilitate the development of targeted interventions to reduce their occurrence. A secondary aim was to assess risk factors for low birth weight (LBW) in the same cohort.

\section{Methods \\ Study design and population}

This was a prospective, longitudinal cohort study of healthy pregnant women who were recruited from 10 health centers in Gasabo District, Kigali Province between September and October 2017.

The inclusion criteria were as follows: a singleton pregnancy at 9-15 gestational weeks as calculated using abdominal ultrasonography and the last menstrual period; absence of HIV and syphilis infection as documented in the participant's records, and the provision of informed consent.

\section{Sampling procedure}

We calculated that with $80 \%$ power, a significance level of 0.05 (two-sided), an expected PTB prevalence rate of $10 \%$, an error margin of $3.5 \%$, and a confidence interval (CI) of $95 \%$, a sample size of 300 participants was required to detect an increased risk for PTB (odds ratio of 2) associated with micronutrient deficiency and infection. However, anticipating a possible dilution of the associations due to a $40 \%$ risk of subject withdrawal or exclusion due to postnatal factors (e.g., home delivery and miscarriage, etc.), we estimated that the total sample size required was 420 participants.

Potential participants were identified by community health workers in charge of maternal and child health at neighborhood health centers. Women who were eligible to participate were asked to report to the health center in their zone for additional information and preliminary screening. The participants from the 10 health centers were transported to the College of Health Sciences at the University of Rwanda. Trained research assistants obtained verbal and written informed consent from participants. 


\section{Data collection process}

After screening and obtaining informed consent, two obstetricians conducted ultrasound screening and two midwives performed vaginal examinations, and collected specimens (blood and vaginal swabs). Six trained enumerators conducted verbal interviews on dietary history and collected demographic data and maternal anthropometric measurements. Laboratory specimens were processed by four laboratory scientists on-site where blood was separated for micronutrient analyses and vaginal swabs collected for bacteria culture.

\section{Analysis of micronutrients and inflammatory biomarkers}

Venous blood samples were collected from non-fasting women in the morning or early afternoon. The laboratory specimens were processed on site by four laboratory scientists. The blood was separated to obtain serum samples, which were aliquoted, placed in polyethylene containers, and frozen at $-80^{\circ} \mathrm{C}$ at University Teaching Hospital of Kigali prior to shipment on dry ice to a laboratory in Germany for the analysis of micronutrients and inflammatory biomarkers. Samples were analyzed for ferritin, soluble transferrin receptors (sTfR), retinol binding protein (RBP), $\alpha_{1}$-acid- glycoproteins (AGP), and $\mathrm{C}$ - reactive protein (CRP) using the combined sandwich enzyme linked immunosorbent assay (ELISA) technique [26].

For interpretation of the micronutrients analysis deficiencies, WHO guidelines were used with the following cutoff points: anemia $(\mathrm{HB}<11 \mathrm{~g} / \mathrm{dl})$ [27], low serum ferritin $<12 \mu \mathrm{g} / \mathrm{L}$ and vitamin A deficiency (retinol binding protein) $\mathrm{RBP}<0.83 \mu \mathrm{mol} / \mathrm{L}$. For inflammatory biomarkers, serum concentrations of $>5 \mathrm{mg} / \mathrm{l} \mathrm{C}$-reactive protein (CRP) and $>1 \alpha_{1}$-acid glycoprotein (AGP), were considered to indicate acute and chronic inflammation respectively [28]. In addition to the venous blood samples, a drop of blood from a finger prick was collected in a microcuvette and assayed on-site using a batteryoperated portable HemoCue to measure the hemoglobin levels, and $\mathrm{HB}<11 \mathrm{~g} / \mathrm{dl}$ was considered to indicate maternal anemia [27].

\section{Screening for genitourinary infection}

Vaginal swabs were collected from each participant to screen for genital infections with subsequent microbial biochemical identification, gram staining, $\mathrm{pH}$ determination, and whiff tests. The isolation and identification of group B streptococci were conducted using a 5\% sheep blood agar culture medium. To diagnose bacterial vaginosis, we used the Nugent' criteria as per standard procedures [29].

The presence of Trichomonas vaginalis was confirmed using wet mount microscopy [30]. The diagnosis of Candida albicans infection was made via cultivation on
Sabouraud' agar, supplemented with antibiotics followed by identification using germ tube test [31]. Chlamydia trachomatis was detected using CORTEZ One-Step Chlamydia Rapicard ${ }^{\mathrm{Tm}}$ [32].

Freshly voided, midstream urine samples were collected in sterile cups. A quantitative urine cultures were conducted by using a $0.001 \mathrm{ml}$ calibrated bacteriological loop to inoculate blood agar according to standard procedures. After bacterial growth was observed, a colony count was done. Significant bacteriuria was defined as a colony count $>10^{5}$ colony forming units (CFU) per milliliter of urine for a single pathogen [33]. The pathogen identification process involved different steps and tests, including wet mount microscopy, colony characteristics analysis, gram staining, catalase test, and analytical profile index (API 20E) followed by a standard oxidase test as a control [34].

\section{Demographic, dietary, and anthropometric data}

Six trained enumerators conducted verbal interviews on dietary history, collected demographic data, and performed maternal anthropometric measurements. The questionnaire for demographic data included items such as maternal age, education, residence, socioeconomic status, health and reproductive history. Specific data on dietary intake were obtained using nutritional food frequency questionnaires, which included the items required to compute the minimum dietary diversity for women (MDD-W) [35]. The MDD-W is a dichotomous indicator of whether or not women aged 15-49 years have consumed at least five out of the ten defined food groups on the previous day or night. This indicator estimates the percentages of women who have micronutrient adequacy and good dietary quality [36].

Anthropometric measurements, including weight and height, were obtained using standard digital scales and a portable stadiometer. Body mass index was calculated by dividing the maternal weight in kilograms by the square of the height in meters, and interpreted as per WHO guidelines [37] as follows: $<18.5 \mathrm{~kg} / \mathrm{m}^{2}$, underweight; 18.5 to $<25 \mathrm{~kg} / \mathrm{m}^{2}$, normal weight; 25.0 to $<30 \mathrm{~kg} / \mathrm{m}^{2}$, overweight; and $\geq 30.0 \mathrm{~kg} / \mathrm{m}^{2}$, obesity. The maternal mid-upper arm circumference (MUAC) was recorded as a proxy indicator of the maternal nutritional status. A MUAC $<23 \mathrm{~cm}$ indicated poor nutritional status, while a $M U A C \geq 23 \mathrm{~cm}$ indicated adequate nutritional status [38].

\section{Statistical analysis}

Data were checked for consistency, coded, entered into Epi-data (version 3.1) and then, exported to SPSS version 20 for analysis. The normality of continuous variables was checked graphically PTB was the main outcome of interest and logistic regression was used to 
assess possible relationships for all predictors including maternal nutritional and infectious disease status. We also assessed risk factors for LBW, defined as birth weight $<2500 \mathrm{~g}$, as a secondary outcome. Means and standard deviations were calculated for all predictors of interest. In building the multivariable logistic regression models, we included any variable with $p \leq 0.25$ using enter command, thereafter, we developed the final multivariable model (restricted model) using backwardstepwise regression, with significance set to $p \leq 0.05$. The results are reported as odds ratios (ORs) with 95\% confidence intervals (CIs). We used the same approach for multivariable analysis for PTB and LBW.

\section{Results}

\section{Socio-demographic and behavioral profile}

A total of 421 women were enrolled in this study, of whom, 367 women (87.2\%) completed the follow- up through delivery. Reasons for loss to follow up or exclusion during follow-up included miscarriage 5.2\% $(n=$ $22)$, delivery at home $0.7 \%(n=3)$ and inability to be contacted via cell phone 6.9\% $(n=29)$ (Fig. 1). The mean gestational age at the time of enrollment into the study was $12.9 \pm 3.5$ weeks; while at the time of the delivery was of $38.8 \pm 2.1$ weeks. The mean age of the participants was $28.12 \pm 6.01$ years; $82.8 \%(n=303)$ of the participants were between the ages of 20 and 35 years. Most of the women had a BMI within the normal range $71.9 \%(n=$

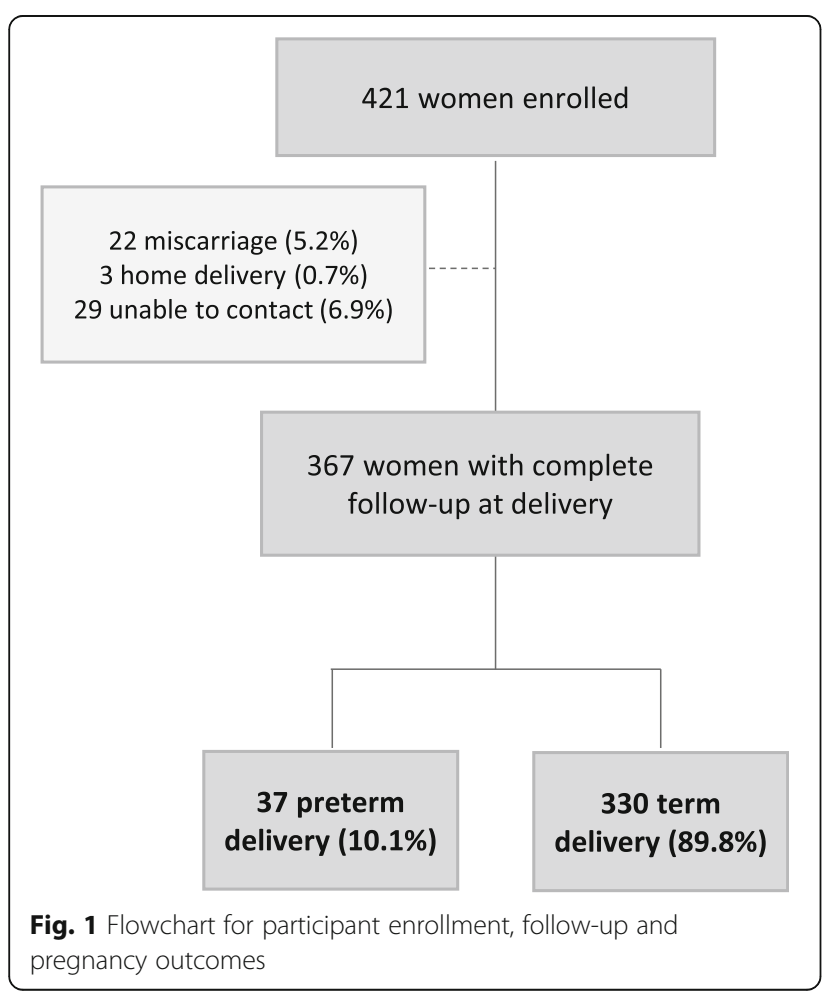

261); did not drink alcohol 77\% $(n=282)$, lived with a partner 93.2\% $(n=340$,$) and reported never having expe-$ rienced gender-based violence $96.2 \%(n=352)$. Slightly more than half of the participants $50.8 \%(n=186)$ reported being unemployed or working as a housewife, and having received no formal education, and about third were from a rural area of Rwanda 67.3\% $(n=247)$. Not living with a partner was the only demographic variable associated with PTB in bivariate analysis. (OR: 3.15 , CI: $1.17,8.46, p=0.02$; (Table 1 ).

\section{Obstetrics and pregnancy outcomes}

Most of the women in this study were multiparous 60.9\% $(n=223)$ and had not experienced a stillbirth 96.7\% $(n=354)$ cesarean section $91.5 \%(n=321)$, a previous preterm labor $(n=306,83.6 \%)$, or miscarriage $85.6 \%$ $(n=309)$. The majority of participants had a vaginal delivery $(81.2 \%, n=298)$ during the current pregnancy.

In total, $10.1 \%(n=37)$ of participants had PTB at a mean of $34 \pm 2.63$ weeks. Participants who delivered at less than 34 weeks gestation represented 3.3\% $(n=12)$ while those who delivered between 34 to 36 weeks' gestation were $6.8 \%(n=25)$. The mean birth weight was $2167.30 \pm 612.14 \mathrm{~g}$ for preterm infants and $3270 \pm$ $392.53 \mathrm{~g}$ for term birth, with mean birth weight of $3159.47 \pm 534.82 \mathrm{~g}$ for the all newborns combined. The percentage of LBW was $2.1 \%(n=7)$ among infants delivered at term, $59.5 \%(n=22)$ among infants born preterm and $7.9 \%(n=29)$ among term and preterm combined. No statistically significant associations were found between PTB and maternal obstetrical history or delivery specifics (Table 2).

\section{Maternal health profile in early pregnancy}

A significant percentage of participants had anemia $(33 \% ; n=122)$ and urinary tract infections (UTIs) $(12.3 \% ; n=45)$ at the time of data collection. The most frequent UTI strain was Escherichia coli $(60 \% ; n=27)$. Additionally, $21.5 \%(n=79)$ of women were diagnosed with Chlamydia; $(5.2 \%, n=19)$ with Trichomonas vaginalis; $(21.5 \%, n=79)$ with Candida albicans $(21.5 \%, n=$ $79)$; and $(19.6 \%, n=72)$ were diagnosed with bacterial vaginosis. The proportion of women experiencing acute and chronic inflammation was $27.3 \%(n=100)$, and $7.9 \%$ $(n=29)$; respectively (Table 3$)$.

Maternal anemia as indicated by low hemoglobin, UTIs, and vaginal chlamydia infection were associated with a greater risk of PTB in the bivariate analyses ( $p=$ $0.001 ; p=0.001$ and $p=0.01$ respectively (Table 3 ).

\section{Maternal nutritional profile in the early pregnancy}

The proportions of women with nutritional deficiencies were as follows: sTfR deficiency, 3.5\% $(n=13)$; RBP (or vitamin A) deficiency, 18.8\% $(n=69)$, and ferritin 
Table 1 Social demographic and behavioral characteristics $(n=367)$

\begin{tabular}{|c|c|c|c|c|c|}
\hline & \multicolumn{2}{|l|}{ PTB } & \multirow[b]{2}{*}{$\begin{array}{l}\text { Total N (\%) } \\
\text { or mean +/-SD) }\end{array}$} & \multicolumn{2}{|l|}{ Univariate } \\
\hline & $\begin{array}{l}\text { Yes ptB N (\%) } \\
\text { or mean +/-SD }\end{array}$ & $\begin{array}{l}\text { NoptB } N(\%) \\
\text { or mean }+/-S D)\end{array}$ & & Crude Odds Ratio (OR) (95\% Cl) & $P$-Value \\
\hline Age in Years $(N=367)$ & $27.95 \pm 6.20$ & $28.14 \pm 6.00$ & $28.12 \pm 6.012$ & $0.99[0.93,1.05]$ & $<0.85$ \\
\hline \multicolumn{6}{|l|}{$\operatorname{Age}(n=367)$} \\
\hline$<20$ & $2(5.4)$ & $16(4.9)$ & $18(4.9)$ & 1 & \\
\hline$\geq 20-35$ & $30(81.1)$ & $273(82.7)$ & $303(82.6)$ & $1.23[.18, .5 .83]$ & 0.96 \\
\hline$>35$ & $5(13.5)$ & $41(12.4)$ & $46(12.5)$ & $.901[.33,2.45]$ & 0.84 \\
\hline Gestational Age(weeks) at recruitment $(n=367)$ & $11.78 \pm 3.86$ & $13.03 \pm 3.48$ & $12.9 \pm 3.54$ & - & - \\
\hline Weight in $\mathrm{Kg}\left(\right.$ mean, SD) $\left(\mathrm{n}^{\mathrm{a}}=363^{*}\right)$ & $53.86 \pm 8.49$ & $57.21 \pm 9.38$ & $56.87 \pm 9.34$ & - & - \\
\hline \multicolumn{6}{|l|}{ Residence $(n=367)$} \\
\hline Urban & $11(29.7)$ & 109(33.0) & $120(32.7)$ & 1 & \\
\hline Rural & $26(70.3)$ & $221(67.0)$ & $247(67.3)$ & $1.16[.55,2.45]$ & 0.25 \\
\hline \multicolumn{6}{|l|}{ Occupation $\left(n^{\mathrm{a}}=366\right)$} \\
\hline Paying Job & $21(56.8)$ & 159(48.3) & $180(49.2)$ & 1 & \\
\hline Housewife & $16(43.2)$ & $170(51.7)$ & $186(50.8)$ & $1.40[.71,2.78]$ & 0.23 \\
\hline \multicolumn{6}{|l|}{ Living with a partner $\left(n^{\mathrm{a}}=365\right)$} \\
\hline Yes & $31(83.8)$ & $309(94.2)$ & $340(93.2)$ & 1 & \\
\hline No & $6(16.2)$ & $19(5.8)$ & $25(6.8)$ & $3.15[1.17,8.46]$ & $0.02^{* *}$ \\
\hline \multicolumn{6}{|l|}{ Educational level $\left(n^{\mathrm{a}}=366\right)$} \\
\hline Never schooled & $17(45.9)$ & 169(51.3) & 186(50.8) & 1 & \\
\hline Primary & $7(18.9)$ & $69(21.0)$ & $76(20.8)$ & $1.01[.40,2.54]$ & 0.98 \\
\hline Secondary or higher & 13(35.1) & $91(27.7)$ & 104(28.4) & $1.42[.66,3.05]$ & 0.36 \\
\hline Body Mass Index (BMI) (continuous) $\left(n^{\mathrm{a}}=363\right)$ & $23.21 \pm 3.51$ & $23.31 \pm 3.55$ & $23.21+3.51$ & & \\
\hline \multicolumn{6}{|l|}{$\operatorname{BMI}\left(N^{\mathrm{a}}=363\right)$} \\
\hline Underweight & $2(5.4)$ & $11(3.4)$ & $13(3.6)$ & 1 & \\
\hline Normal Weight & $30(81.1)$ & $231(70.9)$ & 261(71.9) & $0.71[.15,3.32]$ & 0.67 \\
\hline Overweight & $4(10.8)$ & $68(20.9)$ & $72(19.8)$ & $0.32[.05,1.98]$ & 0.26 \\
\hline Obese & $1(2.7)$ & $16(4.9)$ & $17(4.7)$ & $0.34[.03,4.27]$ & 0.41 \\
\hline \multicolumn{6}{|l|}{ Alcohol use (at least 2-4 times per month) $\left(n^{\mathrm{a}}=366\right)$} \\
\hline Yes & 29(78.4) & 253(76.9) & $84(23.0)$ & 1 & \\
\hline No & $8(21.6)$ & $76(23.1)$ & $282(77.0)$ & $0.92[.40,2.09]$ & 0.83 \\
\hline \multicolumn{6}{|l|}{ Gender-based Violence $\left(n^{\mathrm{a}}=336\right)$} \\
\hline Yes & $37(100)$ & $14(4.3)$ & $14(3.8)$ & 1 & \\
\hline No & $0(0.0)$ & $315(95.7)$ & $352(96.2)$ & $1.02[.04,1.16]$ & 0.90 \\
\hline
\end{tabular}

$\mathbf{n}^{\mathbf{a}}$ Sample size reduced by missing responses among covariates

${ }^{* *} p<0.01,{ }^{*} p<0.5$

deficiency, $19.1 \%(n=70)$. Half of the study cohort $(50 \%$, $n=188)$ did not meet the MDD-W, while $19.8 \%(n=72)$ of women had an MUAC $<23 \mathrm{~cm}$, suggesting malnutrition (Table 4). Having a low MDD-W and a MUAC < $23 \mathrm{~cm}$ were associated with an increased risk of PTB in the bivariate analyses $(p=0.001$ and $p=0.001$, respectively). A lower $s$ TfR neared statistical significance in association with risk for PTB $(p=0.07)$.

In the multivariable logistic regression, the following independent predictors of PTB were identified: anemia $(<11 \mathrm{~g} / \mathrm{dl})(\mathrm{OR}: 4.27$; 95\%CI: $1.85-9.85)$, a UTI in early pregnancy(OR:9.82; 95\%CI: 3.88;24.83), infection with Chlamydia trachomatis(OR: 2.79; 95\%CI: 1.17; 6.63) a low MDD-W (OR: 3.94; CI: 1.57-9.91) and a MUAC < $23 \mathrm{~cm}$ (OR: 3.12, 95\%CI; 1.31; 7.43) (Table 5).

A low MDD-W (OR:3. 19; 95\%CI: 1.23; 8.25), a low MUAC suggestive of malnutrition (OR:3.36, 95\%CI:1.37; 8.26) and maternal urinary tract infections (OR:8.09, 95CI:3.04, 21.57) were independent determinants of LBW (results not shown). 
Table 2 Obstetric history and pregnancy outcomes $(n=367)$

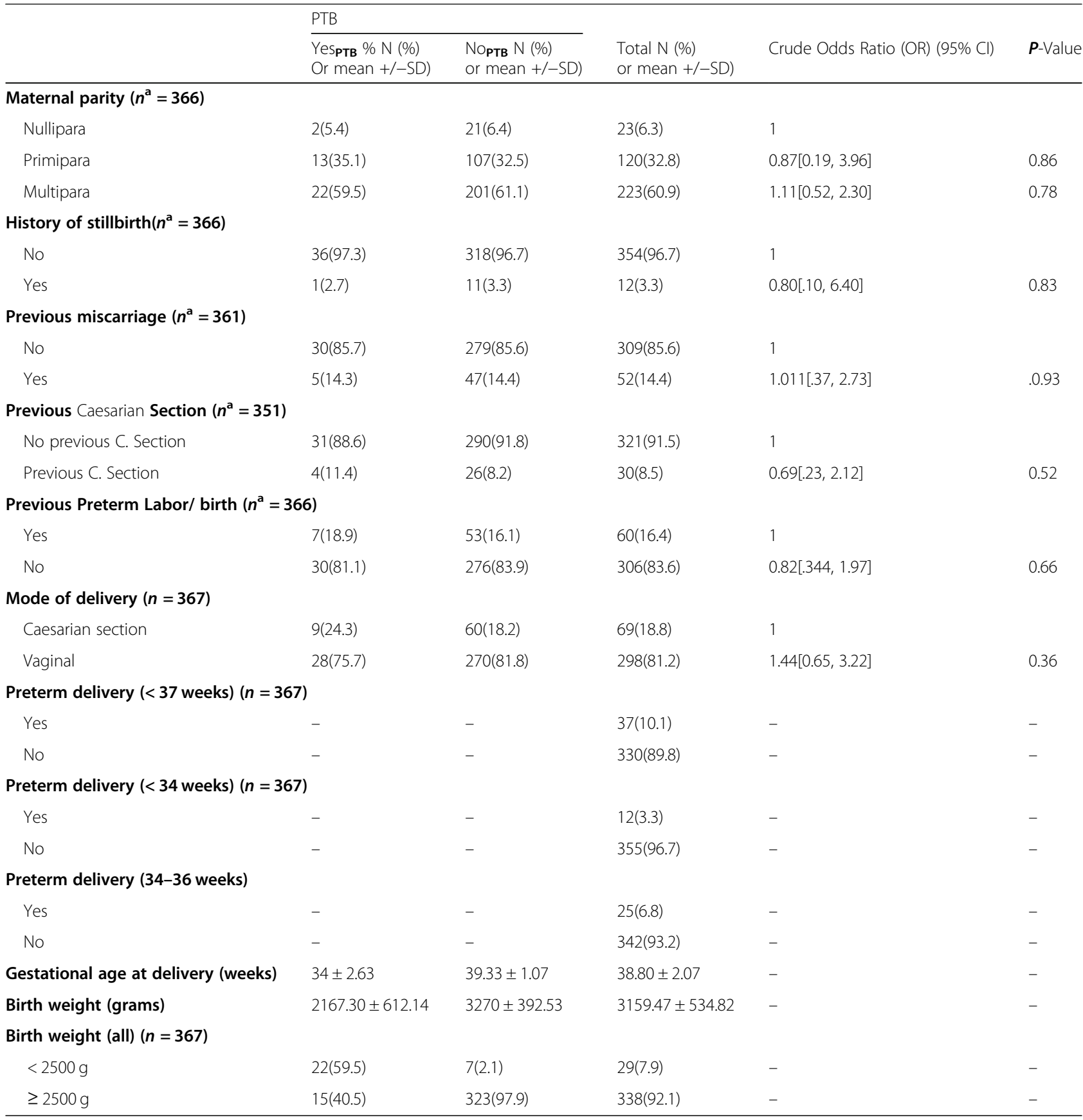

$\mathbf{n}^{\mathbf{a}}$ Sample size reduced by missing responses among covariates

\section{Discussion}

Our study found a $10 \%$ rate of PTB, confirmed by early abdominal ultrasonography, in urban and peri-urban Rwanda. This rates closely aligns with WHO estimates of 9.5\% for sub-Saharan Africa [39] but is lower than the rates reported in East Africa, where the PTB incidence rate was found to be $14.2 \%$ in Tanzania and $18.3 \%$, in Kenya [40, 41]. This discrepancy could be because most of the studies from neighboring countries were conducted in tertiary hospitals where complex obstetrical cases are managed or alternatively due to imprecise gestational age estimation in contrast with our ultrasound confirmed gestation, potentially leading to earlier estimates of pregnancy. Additionally, women with STIs and other infections were referred for treatment in our study, which may have reduced the overall burden of inflammation later in pregnancy, a risk factor for PTB as described below. 
Table 3 Maternal health profile $(n=367)$

\begin{tabular}{|c|c|c|c|c|c|}
\hline & \multicolumn{3}{|l|}{ PTB } & \multicolumn{2}{|l|}{ Univariate } \\
\hline & $\begin{array}{l}\text { YespтB N (\%) } \\
\text { Or mean } \pm \text { SD) }\end{array}$ & $\begin{array}{l}\text { No } \\
\text { or mean } \mathrm{N}(\%) \\
\pm \mathrm{SD})\end{array}$ & $\begin{array}{l}\text { Total N (\%) } \\
\text { or mean } \pm S D)\end{array}$ & Crude Odds Ratio (OR) (95\% Cl) & $\boldsymbol{P}$-Value \\
\hline Hemoglobin & $10.50 \pm 0.97$ & $11.26 \pm 1.11$ & $11.18 \pm 1.12$ & $0.54[0.39,0.74]$ & $0.001^{* *}$ \\
\hline \multicolumn{6}{|l|}{ Anemia $(<11 \mathrm{~g} / \mathrm{dl})(n=367)$} \\
\hline No & $11(29.7)$ & 234(70.9) & $245(66.8)$ & 1 & \\
\hline Yes & $26(70.3)$ & 96(29.1) & 122(33.2) & $5.80[2.74,12.12]$ & $0.001^{* *}$ \\
\hline C Reactive Protein(CRP mg/l) & $4.69 \pm 7.24$ & $5.01 \pm 11.68$ & $4.97 \pm 11.31$ & $0.99[0.96,1.03]$ & 0.87 \\
\hline \multicolumn{6}{|l|}{$\operatorname{CRP}(>5 \mathrm{mg} / \mathrm{l})\left(n^{\mathrm{a}}=366\right)$} \\
\hline Yes & $10(27.0)$ & $90(27.4)$ & $100(27.3)$ & 1 & \\
\hline No & $27(73.0)$ & 239(72.6) & $266(72.7)$ & $0.98[0.45,2.11]$ & 0.96 \\
\hline$a_{1}$-acid glycoprotein $(\mathrm{AGPg} / \mathrm{dl})(n=367)$ & $0.59 \pm 0.25$ & $0.62 \pm 0.40$ & $0.62 \pm 0.39$ & $0.84[0.31,2.24]$ & 0.73 \\
\hline \multicolumn{6}{|l|}{$a_{1}$-acid glycoprotein $(\mathrm{AGP}>1 \mathrm{~g} / \mathrm{l})(n=367)$} \\
\hline Yes & $36(97.3)$ & $302(91.5)$ & 29(7.9) & 1 & \\
\hline No & $1(2.7)$ & $28(8.5)$ & 338(92.1) & $0.30[0.04,2.06]$ & 0.24 \\
\hline \multicolumn{6}{|l|}{ Urinary Tract Infections (UTI) $(n=367)$} \\
\hline No & $21(56.8)$ & $301(91.2)$ & $322(87.7)$ & 1 & \\
\hline Yes & $16(43.2)$ & $29(8.8)$ & $45(12.3)$ & $7.91[3.72,16.81]$ & $0.001^{* *}$ \\
\hline \multicolumn{6}{|l|}{ UTI strain $(n=45)$} \\
\hline Stenotrophomonas maltophilia & $1(6.2)$ & $2(6.9)$ & $3(6.7)$ & - & - \\
\hline Escherchia coli & $3(18.8)$ & 24(82.8) & $27(60.0)$ & - & - \\
\hline Klebsialla pneumoniae & $11(68.8)$ & $1(3.4)$ & $12(26.7)$ & - & - \\
\hline Staphylococcus epidermitis & $1(6.2)$ & $2(6.9)$ & $3(6.7)$ & - & - \\
\hline \multicolumn{6}{|l|}{ Sexually Transmitted Infection(STI) } \\
\hline \multicolumn{6}{|l|}{ Chlamydia $(n=367)$} \\
\hline No & $23(62.2)$ & 265(80.3) & 288(78.50) & 1 & \\
\hline Yes & 14(37.8) & $65(19.7)$ & $79(21.50)$ & $2.48[1.21,5.08]$ & $0.01^{* *}$ \\
\hline \multicolumn{6}{|l|}{ Trichomonas vaginalis $(n=367)$} \\
\hline Yes & $4(10.8)$ & $15(4.5)$ & $19(5.2)$ & 1 & \\
\hline No & $33(89.2)$ & $315(95.5)$ & $348(94.8)$ & $0.39[0.12,1.25]$ & 0.11 \\
\hline \multicolumn{6}{|l|}{ Candida albicans (367) } \\
\hline No & $32(86.5)$ & 256(77.6) & $288(78.5)$ & 1 & \\
\hline Yes & $5(13.5)$ & $74(22.4)$ & $79(21.50)$ & $1.85[0.69 ; 4.91]$ & 0.21 \\
\hline \multicolumn{6}{|l|}{ Bacterial Vaginosis $(n=367)$} \\
\hline No & $32(86.5)$ & 263(79.7) & 295(80.4) & 1 & \\
\hline Yes & $5(13.5)$ & $67(20.3)$ & 72(19.6) & $1.63[0.61,4.34]$ & 0.33 \\
\hline
\end{tabular}

$\mathbf{n}^{\mathbf{a}}$ Sample size reduced by missing responses among covariates

${ }^{* * *} p<0.001,{ }^{* *} p<0.01,{ }^{*} p<0.5$

Micro and macro-nutrient deficiencies as risk factors for PTB and low birthweight

We found that poor maternal nutritional health, as indicated by maternal anemia, low MDD-W, and MUAC < $23 \mathrm{~cm}$, independently predicted PTB. Previous East African studies on maternal anemia and PTB have reported inconsistent findings [41]. It is possible that anemia diagnosed in early pregnancy exerts stronger associations with pregnancy outcomes in terms of PTB as compared to anemia diagnosed later in pregnancy $[42,43]$.

We also found an association of inadequate dietary diversity with LBW; these results are in agreement with previous studies, including a cohort from Norway [10] and Ethiopia [44], in which poor dietary intake was associated with an increased risk of PTB and low birthweight. 
Table 4 Maternal nutritional profile

\begin{tabular}{|c|c|c|c|c|c|}
\hline & \multicolumn{2}{|l|}{ PTB } & \multirow[b]{2}{*}{$\begin{array}{l}\text { Total N (\%) } \\
\text { or mean } \pm \text { SD) }\end{array}$} & \multicolumn{2}{|l|}{ Univariate } \\
\hline & $\begin{array}{l}\text { YesptB N (\%) } \\
\text { or mean } \pm \text { SD) }\end{array}$ & $\begin{array}{l}\text { NoptB } N(\%) \\
\text { or mean } \pm S D)\end{array}$ & & $\begin{array}{l}\text { Crude Odds Ratio } \\
\text { (OR) }(95 \% \mathrm{Cl})\end{array}$ & $\boldsymbol{P}$-Value \\
\hline sTFR (mg/L) (Soluble Transferrin Receptors) $(n=367)$ & $4.88 \pm 1.49$ & $7.42 \pm 1.31$ & $4.83 \pm 1.48$ & $0.07[0.56,1.02]$ & 0.07 \\
\hline No deficiency ( $\leq \mathbf{8 . 3 ~ m g / L ) ~}$ & 35(94.6) & $319(96.7)$ & $354(96.5)$ & 1 & \\
\hline Deficiency (> 8.3 mg/L) & $2(5.4)$ & $11(3.3)$ & $13(3.5)$ & $1.65[0.35,7.78]$ & 0.52 \\
\hline \multicolumn{6}{|l|}{ Retinol Binding Protein (RBP) $(<0.83 \mu \mathrm{mol} / L)(\boldsymbol{n}=\mathbf{3 6 7})$} \\
\hline No deficiency $(\geq 0.83 \mu \mathrm{mol} / L)$ & $30(81.1)$ & 268(81.2) & 298(81.2) & 1 & \\
\hline Deficiency $(<0.83 \mu \mathrm{mol} / \mathrm{L})$ & $7(18.9)$ & $62(18.8)$ & 69(18.8) & $1.01[0.42,2.40]$ & 0.98 \\
\hline $\operatorname{RBP}(\mu \mathrm{mol} / \mathrm{L})(n=367)$ & $1.33 \pm 0.32$ & $1.39 \pm 0.41$ & $1.39 \pm 0.40$ & $0.64[0.26,1.58]$ & 0.34 \\
\hline \multicolumn{6}{|l|}{ Ferritin $(<12 \mu \mathrm{g} / \mathrm{L})(n=367)$} \\
\hline No deficiency ( $\geq 12 \mu \mathrm{g} / \mathrm{L}$ ) & $8(21.6)$ & $62(18.8)$ & 297(80.9) & 1 & \\
\hline Deficiency $(<12 \mu \mathrm{g} / \mathrm{L})$ & 29(78.4) & 268(81.2) & $70(19.1)$ & $1.192(0.52,2.73)$ & 0.67 \\
\hline Ferritin $(<\mu \mathrm{g} / \mathrm{L})$ & $68.52 \pm 36.60$ & $74 \pm 44.56$ & $73.74 \pm 43.82$ & $0.99[0.98,1.01]$ & 0.44 \\
\hline \multicolumn{6}{|l|}{ Minimum Dietary Diversity for Woman (MDDW) $\left(n^{\mathrm{a}}=366\right)$} \\
\hline Adequate MDDW & $8(21.6)$ & 175(53.2) & 183(50) & 1 & \\
\hline Low MDDW & 29(78.4) & 154(46.8) & 183(50) & $4.12[1.82,9.28]$ & $0.001^{* *}$ \\
\hline MDDW (mean, SD) & $3.75 \pm 1.55$ & $4.75 \pm 1.71$ & $4.65 \pm 1.71$ & $0.68[0.54,0.86]$ & \\
\hline \multicolumn{6}{|l|}{ Mid-Upper Arm Circumference $\left(\right.$ MUAC) $\left(n^{\mathrm{a}}=364\right)$} \\
\hline$\geq 23 \mathrm{~cm}$ & $22(59.5)$ & $270(82.6)$ & 292(80.2) & 1 & \\
\hline$<23 \mathrm{~cm}$ & $15(40.5)$ & $57(17.4)$ & $72(19.8)$ & $3.23[1.57,7.00]$ & $0.001^{* *}$ \\
\hline MUAC (Mean, SD) $\left(n^{\mathbf{a}}=364\right)$ & $24.28 \pm 2.81$ & $26.03 \pm 3.22$ & $25.85 \pm 3.22$ & $0.81[0.71,0.92]$ & $0.01^{* *}$ \\
\hline
\end{tabular}

$\mathbf{n}^{\mathbf{a}}$ Sample size reduced by missing responses among covariates

${ }^{* * *} p<0.001,{ }^{* *} p<0.01,{ }^{*} p<0.5$

Our study did not find an association between PTB and maternal iron or folate levels. This was not surprising, as all pregnant women in Rwanda receive iron and folate supplements during antenatal care, and thus, anemia when present, is less likely to be due to iron deficiency, suggesting that other deficits such as VibaminB12 or Selenium might be contributing to the low level of hemoglobin. Low maternal MUAC was also associated with PTB, and maybe a better indication of maternal malnutrition; this is consistent with the results of other studies from sub-Saharan Africa [44, 45].

\section{Infections as risk factors for PTB}

Our study documented an association between UTIs and PTB, which is in agreement with the results of several other studies conducted in the USA, East Africa, and Europe where UTIs were consistently associated with PTB, especially UTIs in early pregnancy [41, 45]. This is because infection may increase the overall inflammatory processes leading to premature labor. Similarly, we found an association between Chlamydia infection and PTB, which is consistent with other previous reports [46].

We found no significant association between Creactive protein (CRP), a biomarker of inflammation, and PTB, differing from other studies where CRP was associated with PTB. However, these other studies collected samples for CRP testing later in pregnancy [47, 48], in contrast with our study. Thus, it is possible that inflammatory processes later in pregnancy versus earlier in pregnancy result in increased risk.

The present study did not find any association between bacterial vaginosis and PTB, in contrast with other studies [49]. This discrepancy might be attributable to the fact that the diagnosis of bacterial vaginosis was performed during early pregnancy in this study; it is possible that the participants received timely medical attention, given that all patients who tested positive were referred to health care providers. In contrast with the association between PTB and infectious etiology, we did not find any association between LBW and other infections except UTIs. Other studies on association between LBW and UTIs reported inconsistent results [50, 51]. Similar to other studies, we did not find any evidence of inflammatory processes contributing to the delivery of infants of LBW [52]. It is possible that the association UTIs versus LBW is mediated by premature delivery rather than growth restriction. In this study, such mediation is illustrated by a strong association between UTIs and PTB. 
Table 5 Multivariate analysis

\begin{tabular}{|c|c|c|c|c|c|c|}
\hline & \multicolumn{3}{|l|}{ Full model } & \multicolumn{3}{|c|}{ Reduced Model } \\
\hline & Odds Ratio (OR) & {$[95 \% \mathrm{Cl}]$} & $p$-Value & $\mathrm{OR}$ & {$[95 \% \mathrm{Cl}]$} & $p$-Value \\
\hline \multicolumn{7}{|l|}{ Social demographics } \\
\hline \multicolumn{7}{|l|}{ Residence } \\
\hline Urban & 1 & & & - & - & - \\
\hline Rural & 1.05 & {$[0.43,2.55]$} & 0.92 & - & - & - \\
\hline \multicolumn{7}{|l|}{ Occupation } \\
\hline Housewife & 1 & & & & & \\
\hline Paying job & 0.90 & {$[0.38,2.13]$} & 0.81 & - & - & - \\
\hline \multicolumn{7}{|l|}{ Marital status } \\
\hline Single & 1 & & & 1 & & \\
\hline Living with a partner & 0.30 & {$[0.08,1.18]$} & 0.08 & 0.33 & {$[0.09,1.19]$} & 0.09 \\
\hline \multicolumn{7}{|l|}{ Body mass index (BMI) } \\
\hline Underweight & 1 & & & & & \\
\hline Normal weight & 0.81 & {$[0.13,5.14]$} & 0.82 & - & - & - \\
\hline Overweight & 0.61 & {$[0.07,5.57]$} & 0.66 & - & - & - \\
\hline Obese & 0.39 & {$[0.02,8.86]$} & 0.55 & - & - & - \\
\hline \multicolumn{7}{|l|}{ Maternal Health profile } \\
\hline \multicolumn{7}{|l|}{$a_{1}$-acid glycoprotein AGP $(g / l)$} \\
\hline No Chronic inflammation ( $\leq 1 \mathrm{~g} / \mathrm{l})$ & 1 & & & & & \\
\hline Chronic inflammation (> $1 \mathrm{~g} / \mathrm{dl}$ ) & 5.97 & {$[0.67 ; 53.21]$} & 0.11 & - & - & - \\
\hline \multicolumn{7}{|l|}{ Hemoglobin Level } \\
\hline$\geq 11 \mathrm{~g} / \mathrm{dl}$ & 1 & & & 1 & & \\
\hline$<11 \mathrm{~g} / \mathrm{dl}$ & 4.35 & {$[1.82 ; 10.38]$} & $0.001^{* *}$ & 4.27 & {$[1.85,9.85]$} & $0.001^{* *}$ \\
\hline \multicolumn{7}{|l|}{ Urinary Tract Infections (UTIs) } \\
\hline No & 1 & & & 1 & & \\
\hline Yes & 11.14 & {$[3.94 ; 31.49]$} & $0.001^{* *}$ & 9.82 & {$[3.88,24.83]$} & $0.001^{* *}$ \\
\hline \multicolumn{7}{|l|}{ Chlamydia } \\
\hline No & 1 & & & 1 & & \\
\hline Yes & 2.66 & {$[1.06 ; 6.69]$} & $0.04^{*}$ & 2.79 & {$[1.17,6.63]$} & $0.05^{*}$ \\
\hline \multicolumn{7}{|l|}{ Trichomonas vaginalis } \\
\hline No & 1 & & & & & \\
\hline Yes & 1.17 & {$[0.22 ; 6.15]$} & 0.85 & - & - & - \\
\hline \multicolumn{7}{|l|}{ Candida albicans } \\
\hline No & 1 & & & & & \\
\hline Yes & 1.50 & {$[0.47 ; 4.72]$} & 0.48 & - & - & - \\
\hline \multicolumn{7}{|l|}{ Maternal nutritional profile } \\
\hline \multicolumn{7}{|l|}{ sTFR } \\
\hline No deficiency $(\geq 0.83 \mu \mathrm{mol} / \mathrm{l})$ & 1 & & & & & \\
\hline Deficiency $(<0.83 \mu \mathrm{mol} / \mathrm{l})$ & 1.25 & {$[0.15 ; 10.39]$} & 0.84 & - & - & - \\
\hline \multicolumn{7}{|l|}{ MDDW } \\
\hline Requirements met & 1 & & & 1 & & \\
\hline Requirements not met & 4.29 & {$[1.65 ; 11.20]$} & $0.003^{*}$ & 3.94 & {$[1.57 ; 9.91]$} & $0.004^{* *}$ \\
\hline \multicolumn{7}{|l|}{ MUAC } \\
\hline$\geq 23 \mathrm{~cm}$ & 1 & & & 1 & & \\
\hline
\end{tabular}


Table 5 Multivariate analysis (Continued)

\begin{tabular}{|c|c|c|c|c|c|c|}
\hline & \multicolumn{3}{|l|}{ Full model } & \multicolumn{3}{|c|}{ Reduced Model } \\
\hline & Odds Ratio (OR) & {$[95 \% \mathrm{Cl}]$} & $p$-Value & $\mathrm{OR}$ & {$[95 \% \mathrm{Cl}]$} & $p$-Value \\
\hline$<23 \mathrm{~cm}$ & 3.01 & {$[1.13 ; 8.02]$} & 0.03 & 3.12 & {$[1.31 ; 7.43]$} & $0.01^{*}$ \\
\hline
\end{tabular}

\section{Demographic data and obstetric history as risk factors for PTB}

We found no association between the maternal level of education and PTB, which is in line with a study conducted in Kenya, where maternal education was not associated with PTB [41]. However, the findings of our study are different from those of a meta-analysis conducted in European countries, where maternal level of education was linked to an appreciable risk of PTB [53]. In our study, $50.8 \%$ of participants reported receiving no formal education, and $20.8 \%$ reported receiving only primary education, which is likely comparable to other developing areas of sub-Saharan Africa. It is possible that there may be less difference between participants with minimal levels of education. We also found that multiparity was not associated with PTB, which conflicts with the results of other studies reporting that multiparous women were more likely to deliver sooner than predicted [41]. The PTB risk from multiparous pregnancy is due to uterine stretching from previous pregnancies. However, it is possible that the higher PTB rates in multiparous women are confounded by advanced maternal age regardless of parity [54]. The majority of our participants $(82.6 \%)$ were in the age range of 20 to 35 -years, which explains why parity was not associated with PTB in our study.

We also found that several factors related to obstetric history were not associated with PTB. History of cesarean delivery (8.5\%) was not associated with PTB, which differs from other studies [55]. It is possible that our study was not powered to find statistical differences as our sample size was small. Our study also did not find an association between a history of PTB, stillbirth, or abortion and PTB in the current pregnancy, in contrast with other studies [40, 56]. However, the risk of PTB can be mitigated by a prior full-term birth, depending on the gestational age [57]. For example, among women with a history of a second-trimester loss, those with a prior full-term birth were $88 \%$ less likely to have a recurrent PTB than those without a prior full-term birth [42]. We did not collect data on previous full-term delivery among women who reported a previous preterm delivery; as such, it is possible that the participants had a history of full-term delivery, which diluted the effect of previous PTB, stillbirth, or abortion on recurrent PTB in the current pregnancy.

\section{Strengths and limitations of the study}

There are strengths and limitations of our study. The strengths of the study include the prospective cohort design which minimized selection biases and the use of abdominal ultrasonography and last menstrual period (LMP) to assess gestational age. The recruitment of women in early pregnancy (9-15 weeks) through the use of the community health workers (CHW) was also a strength of the study. The limitations of the study include the collection of nutrition and infection data at a single time point during early pregnancy. Risk factors associated with a change in nutritional status or the potential impact of genitourinary infections across the duration of the pregnancy could not be accounted for. Participants who were clinically diagnosed with trichomonas vaginalis, vulvovaginal candidiasis or any other unusual vaginal discharge or ulcerations were referred to their respective health facilities for treatment. Therefore, early treatment of these infections might have diluted their effects on preterm delivery. As for nutritional deficiencies, it is a routine practice in Rwanda that all pregnant women receive iron pills during antenatal care; consequently, the impact of the iron deficiencies cannot be counted for. Other vitamin and mineral levels such as Vitamin B12 and selenium were not measured. Therefore, we are not able to discuss the effects of these biomarkers on risks for PTB. Lastly, further research is needed to investigate other genitourinary infections, such as gonorrhea, HIV, syphilis and the differential impact on risk for PTB compared with infections assessed in this study. Women with either HIV or syphilis were excluded from this study.

\section{Conclusions}

PTB is a concern among women in the Gasabo district of Rwanda. Maternal nutritional status, maternal anemia, inadequate MDD-W for women, low MUAC, and genital urinary infections were independent determinants of PTB. Some of the same nutritional risk factors were also independently associated with LBW (low MUAC and MDD-W); however, fewer infectious disease risk factors were associated with LBW except UTIs suggesting more of infectious disease/inflammatory process in PTB versus LBW. Thus, policymakers should expand maternal nutritional counseling and extend screening for nutritional deficiencies and genitourinary infections among pregnant women during antenatal care. Nutritional 
counseling will also help reduce the burden of LBW in developing countries such as Rwanda.

\section{Policy implications}

We found associations between poor maternal nutritional health and the risk of both PTB and LBW. Frontline health staff such as community health workers (CHWs) and relevant health facilities need to work with at risk women to improve the access, availability, and utilization of nutritious foods. For example, household members could be trained on how to produce biofortified crops, develop kitchen gardens, rear and produce of small livestock as well as use manure to boost production from the kitchen gardens and fields.

Rwanda is currently implementing the strategies to improve maternal, infant and young child feeding and hygiene behaviors. Currently, pregnant women from low-income households receive $4.5 \mathrm{~kg}$ flour of shisha kibondo to make fortified porridge from the first antenatal visit. The provision extends to the lactation period and stops when the newborn is 5 months old. Further studies are needed to assess whether this program should be broadened to women of all socioeconomic backgrounds given the lack of association we found between SES and PTB.

Currently, systematic screening of syphilis and HIV is standard practice during antenatal care in Rwanda. Early detection and treatment of maternal genitourinary tract infections may offer a potentially low-cost, high-impact intervention to prevent both PTB and LBW. Screening and treatment of UTIs should be incorporated at the initial antenatal care visit and all follow-up visits.

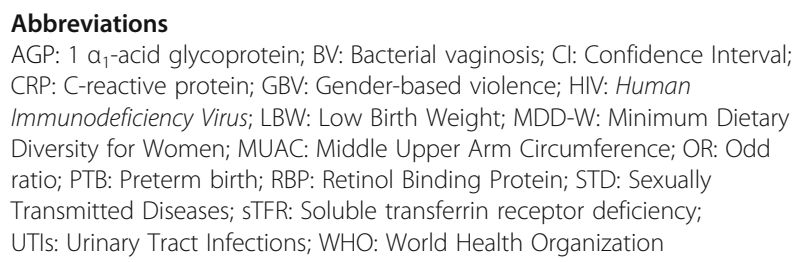

\section{Acknowledgements}

Authors are thankful to the Government of Rwanda through the Ministry of Health, staffs of health centers, Medical Directors of hospitals in Gasabo for their collaboration. We are thankful to data collectors, supervisors and study participants for their devoted time.

\footnotetext{
Authors' contributions

EN, AU, AM, CMM, SR designed research protocol, NS, PM, NM revised the research protocol. AU, DN, contributed to data collection; EN, JW, NS contributed to data analysis, MN, EJC. Participated in the drafting and editing of the manuscript. All authors reviewed, edited, contributed and approved the final version of the manuscript.

\section{Funding}

This study was funded by the East Africa Preterm Birth Initiative, a multi-year, multi-country effort generously funded by the Bill and Melinda Gates Foundation and the funding include publication charges (Investment ID: OPP1107312). The funder of the study had no role in study design, data collection, data analysis or interpretation or writing the report/manuscript.
}

\section{Availability of data and materials}

Availability of the datasets are available from the corresponding author on reasonable request at(etiennen70@gmail.com), while waiting all permissions for deposit in public repositories.

\section{Ethics approval and consent to participate}

The Institution Review Board (IRB) at the College of Medicine and Health Sciences (University of Rwanda) approved the study protocol along with Research Unit at the Rwanda Ministry of Health (Approval notice: No213/ CMHS IRB/2017). All participants signed consent prior to participation and were allowed to stop the participation without prejudice.

\section{Consent for publication}

Not applicable.

\section{Competing interests}

The authors declare that they have no competing interests.

\section{Author details}

${ }^{1}$ University of Rwanda College of Medicine and Health Sciences School of Health Sciences, P.O. Box: 3538, Kigali, Rwanda. ${ }^{2}$ University of Rwanda College of Medicine and Health Sciences School of Public Health, P.O. Box: 3538, Kigali, Rwanda. ${ }^{3}$ University of Rwanda College of Medicine and Health Sciences school of Medicine and Pharmacy, P.O. Box: 3538, Kigali, Rwanda. ${ }^{4}$ Lillian Carter Center for Global Health and Social Responsibility, Nell Hodgson Woodruff School of Nursing, Emory University, Atlanta, GA, USA.

${ }^{5}$ Columbia University School of Nursing, New York, NY 10032, USA.

${ }^{6}$ University of California San Francisco, Institute for Global Health Sciences, San Francisco, USA.

Received: 16 November 2019 Accepted: 27 May 2020

Published online: 03 June 2020

\section{References}

1. March of Dimes, PMNCH, Save the Children W. World Health Organization born too soon. 2012.

2. Moutquin JM. Classification and heterogeneity of preterm birth. BJOG. 2003; 110(SUPPL. 20):30-3.

3. Johanzon M, Ödesjö H, Jacobsson B, Sandberg K, Wennerholm UB. Extreme preterm birth: onset of delivery and its effect on infant survival and morbidity. Obstet Gynecol 2008;111(1):42-50.

4. Menon R. Spontaneous preterm birth, a clinical dilemma: etiologic, pathophysiologic and genetic heterogeneities and racial disparity. Acta Obstet Gynecol Scand. 2008;87(6):590-600.

5. Van Den Broek NR, Jean-Baptiste R, Neilson JP. Factors associated with preterm, early preterm and late preterm birth in Malawi. PLoS One. 2014;9:3.

6. Collins A, JLW J-HW. Why are preterm newborns at increased risk of infection? Arch Dis Child Fetal Neonatal Ed. 2018;103(4):2017-313595.

7. Blencowe H, Lee ACC, Cousens S, Bahalim A, Narwal R, Zhong N, et al. Preterm birth-associated neurodevelopmental impairment estimates at regional and global levels for 2010. Pediatr Res. 2013;74(SUPPL. 1):17-34.

8. Fuchs F, Monet B, Ducruet T, Chaillet N, Audibert F. Effect of maternal age on the risk of preterm birth: A large cohort study. Obstet Gynecol Surv. 2018;73(6):340-2.

9. Halimiasl A, Safari S, Hamrah MP. Epidemiology and related risk factors of preterm labor as an obstetrics emergency. Emergency. 2017;5:1.

10. Englund-Ögge L, Brantsæter AL, Sengpiel V, Haugen M, Birgisdottir BE, Myhre R, et al. Maternal dietary patterns and preterm delivery: results from large prospective cohort study. BMJ. 2014;348(March):1-18. Available from:. https://doi.org/10.1136/bmj.g1446.

11. Alfirevic Z, Stampalija T, Medley N. Cervical stitch (cerclage) for preventing preterm birth in singleton pregnancy. Cochrane Database Syst Rev. 2017;(6): CD008991. https://doi.org/10.1002/14651858.CD008991.pub3.

12. Kondracki AJ, Hofferth SL. A gestational vulnerability window for smoking exposure and the increased risk of preterm birth: how timing and intensity of maternal smoking matter. Reprod Health. 2019;16(1):1-10.

13. Lilliecreutz C, Larén J, Sydsjö G, Josefsson A. Effect of maternal stress during pregnancy on the risk for preterm birth. BMC Pregnancy Childbirth. 2016;16(1):1-8.

14. Shimaoka M, Yo Y, Doh K, Kotani Y, Suzuki A, Tsuji I, et al. Association between preterm delivery and bacterial vaginosis with or without 
treatment. Sci Rep [Internet]. 2019;9(1):1-8. Available from:. https://doi.org/ 10.1038/s41598-018-36964-2.

15. Cram LF, Zapata MI, Toy EC, Baker B. Genitourinary infections and their association with preterm labor. Am Fam Physician. 2002;65(2):241-8.

16. Verma I, Avasthi K, Berry V. Urogenital infections as a risk factor for preterm labor: A hospital-based case-control study. J Obstet Gynecol India. 2014; 64(4):274-8.

17. Mann JR. M S, gill T. sexually transmitted infection is associated with increased risk of preterm birth in South Carolina women insured by medicaid. J Matern Neonatal Med. 2010;23(6):563-8.

18. Reekie J, Roberts C, Preen D, Hocking JS, Donovan B, Ward J, et al. Chlamydia trachomatis and the risk of spontaneous preterm birth, babies who are born small for gestational age, and stillbirth: a population-based cohort study. Lancet Infect Dis. 2018;18(4):452-60.

19. Nadeau HCGG, Subramaniam A, Andrews WW. Infection and preterm birth. Semin Fetal Neonatal Med. 2016;21(2):100-5. Available from:. https://doi.org/ 10.1016/j.siny.2015.12.008.

20. Kenny LC, Kell DB. Immunological Tolerance, Pregnancy, and Preeclampsia: The Roles of Semen Microbes and the Fathert. Front Med. 2018;4(January):239.

21. Carmichael SL, Yang W, Shaw GM. Maternal dietary nutrient intake and risk of preterm delivery Suzan. Am J Perinatol. 2008;23(1):1-7.

22. Rahmati S, Azami M, Badfar G, Parizad N, Sayehmiri K. The relationship between maternal anemia during pregnancy with preterm birth: a systematic review and meta-analysis. J Matern Neonatal Med. 2018;7058:1-11.

23. USAID. Rwanda: Profile of preterm and low birth weight prevention and care. 2016.

24. Donahue Angel M, Berti P, Siekmans K, Tugirimana PL, Boy E. Prevalence of Iron deficiency and Iron deficiency Anemia in the northern and southern provinces of Rwanda. Food Nutr Bull. 2017;38(4):554-63.

25. National Institute of Statistics of Rwanda (NISR) M of, Health (MOH) [Rwanda] II. Rwanda demographic and health survey 2014-15 final report [Internet]. 2016. 307 p. Available from: https://dhsprogram.com/pubs/pdf/ FR316/FR316.pdf.

26. Erhardt JG, Estes JE, Pfeiffer CM, Biesalski HK, Craft NE. Combined measurement of ferritin, soluble transferrin receptor, retinol binding protein, and C-reactive protein by an inexpensive, sensitive, and simple Sandwich enzyme-linked Immunosorbent assay technique. J Nutr. 2018; 134(11):3127-32.

27. World Health Organization. Haemoglobin Concentrations for the Diagnosis of Anaemia and Assessment of Severity. Miner Nutr Inf Syst World Heal Organ; 2013. p. 1-6.

28. Thurnham DI, Mccabe LD, Haldar S, Wieringa FT, Northrop-clewes CA, Mccabe GP. Adjusting plasma ferritin concentrations to remove the effects of subclinical inflammation in the assessment of iron deficiency: 2018; (August):546-555.

29. Rao DSR, Pindi DKG, Rani DU, Sasikala DG, Kawle DV. Diagnosis of bacterial Vaginosis: Amsel's criteria vs Nugent's scoring. Sch J Appl Med Sci. 2016;4(6): 2027-31.

30. Patil M, Nagamoti J, Metgud S. Diagnosis of Trichomonas vaginalis from vaginal specimens by wet mount microscopy, in pouch TV culture system, and PCR. J Glob Infect Dis. 2012;4(1):22.

31. Babić M, Hukić M. Candida albicans andon-albicans species as etiological agent of vaginitis in pregnant and non-pregnant women. Bosn J Basic Med Sci. 2010;10(1):89-97.

32. Hislop J, Quayyum Z, Flett G, Boachie C, Fraser C, et al. Systematic review of the clinical effectiveness and cost-effectiveness of rapid point-of-care tests for the detection of genital chlamydia infection in women and men. Health Technol Assess (Rockv). 2010;14(29):i-125 Available from: http://www. embase.com/search/results?subaction=viewrecord\&from=export\&id=L35 9134054\%0Ahttp://dx.doi.org/10.3310/hta14290.

33. Niels F-M, Espersen F. Evaluation of calibrated 1 and $10 \mathrm{Mul}$ loops and dipslide as compared to pipettes for detection of low count bacteriuria in vitroNote. Apmis. 2003;108(7-8):525-30

34. Venter SN, Lotter HS, Haas DW, MacDonald L. The use of the analytical profile index in the identification of activated sludge bacteria. Problems and solutions. Water SA. 2000;15(4):4738

35. FAO and FHI 360. Minimum Dietary Diversity for Women- A Guide to Measurement. Minimum Dietary Diversity for Women: A Guide for Measurement. 2016. 82.
36. Martin-Prevel Y, Arimond M, Allemand P, Wiesmann D, Ballard TJ, Deitchler $M$, et al. Development of a Dichotomous Indicator for Population-Level Assessment of Dietary Diversity in Women of Reproductive Age. Curr Dev Nutr. 2017;1 (12):cdn.117.001701.

37. World Health Organization. Obesity: Preventing and Managing the Global Epidemic - WHO Technical Report Series. WHO Technical Report Series. 2000.

38. Tang AM et al. Determining a Global Mid-Upper Arm Circumference Cutoff to Assess Malnutrition in Pregnant Women. Washington, DC:; 2016.

39. Linked to "Born too Soon: The Global Action Report on Preterm Birth." Country data and rankings for preterm birth EMBARGO UNTIL MAY 2ND 2012. "Born too Soon Glob Action Rep Preterm Birth" [Internet]. 2012;6-9. Available from: http://www.who.int/pmnch/media/news/2012/201204_ borntoosoon_countryranking.pdf.

40. Temu TB, Masenga G, Obure J, Mosha D, Mahande MJ. Maternal and obstetric risk factors associated with preterm delivery at a referral hospital in northern-eastern Tanzania. Asian Pac J Reprod. 2016;5(5):365-70. Available from:. https://doi.org/10.1016/j.apjr.2016.07.009.

41. Peter W, Wasunna A, Wamalwa D, Ng'ang'a P. Prevalence and factors associated with preterm birth at kenyatta national hospital. BMC Pregnancy Childbirth. 2018:18:107.

42. Purisch SE, Turitz AL, Elovitz MA, Levine LD. The effect of prior term birth on risk of recurrent spontaneous preterm birth. Am J Perinatol. 2018;25(3):289-313.

43. Ronkainen J, Lowry E, Heiskala A, Uusitalo I, Koivunen P, Kajantie E, et al. Maternal hemoglobin associates with preterm delivery and small for gestational age in two Finnish birth cohorts. Eur J Obstet Gynecol Reprod Biol. 2019;238:44-8. Available from. https://doi.org/10.1016/j. ejogrb.2019.04.045.

44. Girma S, Fikadu T, Agdew E, Haftu D, Gedamu G, Dewana Z, et al. Factors associated with low birthweight among newborns delivered at public health facilities of Nekemte town, West Ethiopia: A case control study. BMC Pregnancy Childbirth. 2019;19(1):1-6.

45. Berhe T, Gebreyesus H, Desta H. Determinants of preterm birth among mothers delivered in central zone hospitals, Tigray, northern Ethiopia. Bmc Res Notes. 2019;12(1):10-5. Available from. https://doi.org/10.1186/s13104019-4307-z.

46. Schmidt R, Muniz RR, Cola E, Stauffert D, Silveira MF, Miranda AE. Maternal chlamydia trachomatis infections and preterm births in a University Hospital in Vitoria, Brazil. PLoS One. 2015;10(10):4-11.

47. Bullen BL, Jones NM, Holzman CB, Tian Y, Senagore PK, Thorsen P, et al. Creactive protein and preterm delivery: clues from placental findings and maternal weight. Reprod Sci. 2013;20(6):715-22.

48. Lobo SM. Sequential C-reactive protein measurements in patients with serious infections: does it help? Crit Care. 2012;16(3):130-1.

49. Wen A, Srinivasan U, Goldberg D, Owen J, Marrs CF, Misra D, et al. Selected vaginal bacteria and risk of preterm birth: an ecological perspective. J Infect Dis. 2014;209(7):1087-94.

50. Kpikpitse D, Azanu W, John ME, Doe PF, Ebu NI. Maternal and perinatal outcomes among pregnant women with Urinary Tract Infections. Int J Curr Res. 2016;(November):2-8.

51. Schieve LA, Handler A, Hershow R, Persky V, Davis F. Urinary tract infection during pregnancy: its association with maternal morbidity and perinatal outcome. Am J Public Health. 1994;84(3):405-10.

52. Romero R, Gotsch F, Pineles B, Kusanovic JP. Inflammation in Pregnancy: Its Roles in Reproductive Physiology, Obstetrical Complications, and Fetal Injury. Nutr Rev. 2007;65(SUPPL.3):S194.

53. Ruiz M, Goldblatt P, Morrison J, Kukla L, Švancara J, Riitta-Järvelin M, et al. Mother's education and the risk of preterm and small for gestational age birth: A DRIVERS meta-analysis of 12 European cohorts. J Epidemiol Community Health. 2015;69(9):826-33.

54. Huang A, Ji Z, Zhao W, Hu H, Yang Q, Chen D. Rate of gestational weight gain and preterm birth in relation to prepregnancy body mass indices and trimester: A follow-up study in China. Reprod Health. 2016;13(1):1-7. Available from:. https://doi.org/10.1186/s12978016-0204-2

55. Williams CM, Asaolu I, Chavan NR, Williamson LH, Lewis AM, Beaven $L$, et al. Previous cesarean delivery associated with subsequent preterm birth in the United States. Eur J Obstet Gynecol Reprod Biol. 2018:229:88-93. Available from. https://doi.org/10.1016/j.ejogrb. 2018.08.013. 
56. Kelkay B, Omer A, Teferi Y, Moges Y. Factors associated with singleton preterm birth in Shire Suhul general hospital, northern Ethiopia, 2018. J Pregnancy. 2019;2019.

57. Barros FC, Bhutta ZA, Batra M, Hansen TN, Victora CG, Rubens CE. Global report on preterm birth and stillbirth (3 of 7): evidence for effectiveness of interventions. BMC Pregnancy Childbirth. 2010;10(S1):1-16.

\section{Publisher's Note}

Springer Nature remains neutral with regard to jurisdictional claims in published maps and institutional affiliations.

Ready to submit your research? Choose BMC and benefit from:

- fast, convenient online submission

- thorough peer review by experienced researchers in your field

- rapid publication on acceptance

- support for research data, including large and complex data types

- gold Open Access which fosters wider collaboration and increased citations

- maximum visibility for your research: over $100 \mathrm{M}$ website views per year

At BMC, research is always in progress.

Learn more biomedcentral.com/submissions 